\title{
O SURGIMENTO DO PROGRAMA PARCELADAS E SUA CONSOLIDAÇÃO NO MÉDIO ARAGUAIA
}

\section{THE DEVELOPMENT OF THE PARCELED PROGRAM AND ITS CONSOLIDATION IN \\ THE MEDIUM ARAGUAIA}

\author{
Vânia Horner de Almeida \\ Mestra em Educação para Ciências e Matemática (IFGO) \\ Professora da Escola Estadual Vila Rica \\ E-mail:vaniahorner@hotmail.com \\ Maria do Rosário Soares Lima \\ Mestra em História (UNEMAT) \\ Professora da Escola Estadual Vila Rica e da UNEMAT \\ E-mail:mariadorosariovilarica@gmail.com
}

\begin{abstract}
Resumo: Este trabalho tem como objetivo demonstrar o contexto histórico do Programa Parceladas na região do Araguaia, bem como verificar as contribuições do Programa Parceladas na formação inicial dos egressos do curso de Matemática. Para isso, analisamos documentos dos cursos de graduação em Matemática ofertados no período de 2003 a 2011. Os documentos selecionados foram: ementas do projeto político pedagógico, relatório de autorização e processo de reconhecimento dos cursos, planos de aula dos professores que ministraram aulas nas disciplinas de Educação Matemática e o questionário aplicado aos alunos egressos dessas turmas. Os resultados encontrados possibilitaram identificar o processo de consolidação do Programa Parceladas.
\end{abstract}

Palavras-chave: Programa Parceladas; Araguaia; Formação inicial.

Abstract: This paper aims to demonstrate the historical context of the Parceladas Program in the Araguaia region, as well as to verify the contributions of the Parceladas Program in the initial training of the graduates of the Mathematics course. For that, we analyzed documents of the degree courses offered in Mathematics from 2003 to 2011. The documents selected were: the menus of the pedagogical political project; authorization report and course recognition process; the lesson plans of teachers who taught classes in the subjects of Mathematics Education and the questionnaire applied to the students who graduated from these classes. The results found made it possible to identify the consolidation process of the Parceladas Program. Keywords: Parceladas Program; Araguaia; Initialformation.

\section{Introdução}

Este trabalho descreve de forma resumida parte da história da Universidade Estadual de Mato Grosso - UNEMAT, enfatizando o Programa Parceladas. Apresenta também um pouco do cenário histórico da situação educacional que antecede o período do surgimento do programa, bem como o perfil dos alunos cursistas e egressos dos cursos de Licenciatura em Matemática e a visão desses sujeitos em relação ao Programa parceladas. 
O contexto histórico da educação, na região do Médio Araguaia, é bastante dinâmico e bem anterior ao Programa Parceladas (Projeto parceladas, nome recebido inicialmente) que foi implantado pela Universidade do Estado de Mato Grosso, por meio de reivindicações de pessoas ligadas à educação, aos movimentos sociais, à igreja e aos sindicatos.

Desse modo, neste trabalho apresenta-se de forma abreviada um pouco da história da Universidade Estadual de Mato Grosso, especialmente do Programa Parceladas e o cenário histórico da situação educacional que antecipa o momento do nascimento do programa. Tem por objetivo demonstrar o contexto histórico do Programa em estudo e verificar as contribuições deste na formação inicial dos egressos do curso de Matemática.

Os procedimentos metodológicos sustentam-se na pesquisa qualitativa. A opção pela metodologia da pesquisa qualitativa dá-se com intuito de privilegiar o ambiente natural e a realidade na qual os fatos aconteceram ou acontecem, as falas, os sentimentos, as vivências da vida social e profissional dos sujeitos investigados. Justifica-se, ainda, a opção metodológica da pesquisa pela afirmação de que, na investigação qualitativa, os dados colhidos não são expressos somente através de números. O foco principal da pesquisa com a abordagem qualitativa são as falas dos sujeitos que podem ser expressas nos registros escritos (BOGDAN e BIKLEN, 1994; LÜDKE e ANDRÉ, 1986).

Para isso, analisamos documentos dos cursos de graduação em Matemática ofertados no período de 2003 a 2011. Os documentos selecionados foram: relatório de autorização, processo de reconhecimento dos cursos e questionário aplicado aos alunos egressos dessas turmas. Os resultados encontrados possibilitaram identificar o processo de consolidação do Programa Parceladas, além de contribuir com a formação dos licenciados na construção do conhecimento das diferentes metodologias de ensino de Matemática.

\section{A Universidade Estadual de Mato Grosso - UNEMAT}

O processo histórico da Universidade do Estado de Mato Grosso - UNEMAT $^{1}$ está vinculado à criação do Instituto Superior de Cáceres, no ano de 1978, que faz com que a Universidade tenha em sua história a origem de ter nascida no interior. O Instituto de Ensino Superior de Cáceres (IESC) foi criado com base na Lei no 703 e no Decreto Municipal 190

${ }^{1}$ Para este texto, no que diz respeito a sua constituição e ao processo histórico da UNEMAT, utilizamos dados disponíveis na página da web da UNEMAT. http://www.novoportal.unemat.br/ e do site: http://pt.wikipedia.org/wiki/Universidade_do_Estado_de_Mato_Grosso 
vinculado à Secretaria Municipal de Educação e à Assistência Social. Com a finalidade de agenciar o ensino superior e a pesquisa passou, então, a funcionar como Entidade Autárquica Municipal.

Em 30 de maio de 1984, o Decreto Federal 89.719 aprovou o funcionamento dos cursos ministrados pelo Instituto.

Em 1985 designou a Fundação Centro Universitário de Cáceres (FUCUC), entidade fundacional, autônoma, ligada à Secretaria de Educação e Cultura do Estado de Mato Grosso, regulamentada pela Lei Estadual 4.960, de 19 de dezembro. Essa entidade tinha por objetivo incentivar à pesquisa e o estudo dos diferentes campos do saber, bem como a publicação científica, técnica e cultural.

Na década de 1990, mais especificamente no ano de 1992 a Fundação Centro Universitário de Cáceres passou a denominar-se Fundação de Ensino Superior de Mato Grosso (FESMAT). Em 15 de dezembro de 1993, através da Lei Complementar 30, fundou-se a Universidade do Estado de Mato Grosso-UNEMAT sustentada pela Fundação Universidade do Estado de Mato Grosso - FUNEMAT.

Nessa década ocorreu a grande expansão da instituição para outras regiões de Mato Grosso com a abertura de Núcleos fora de Cáceres, município sede. O primeiro a ser criado foi em 1990 em Sinop; logo após, criou-se os núcleos de Alta Floresta, Alto Araguaia, Nova Xavantina, Pontes e Lacerda e Luciara, em 1991 (data e local de lugar de nascimento do Projeto Parceladas); Barra do Bugres e Colíder em 1994; Tangará da Serra em 1995; Juara em 1999 que entrou em efetivo exercício em 2001.

A Universidade foi credenciada pelo Conselho Estadual de Educação em 10 de agosto de 1999, ficando regulamentada por cinco anos, passando a gozar de autonomia didática, científica e pedagógica.

Atualmente (2018), a UNEMAT completa 40 anos de atuação. Ela está presente em 108 municípios mato-grossenses, constituindo assim, 13 campi, 10 núcleos pedagógicos e 18 pólos educacionais de Ensino à Distância. Atende em torno de 21 mil acadêmicos em 60 cursos presenciais. Para atender a essa demanda estudantil, a Universidade possui um corpo docente composto de aproximadamente 1.100 professores entre mestres e doutores. A instituição conta com um doutorado institucional, dois doutorados interinstitucionais (DINTER), três doutorados em rede, oito mestrados institucionais, um mestrado interinstitucional (MINTER), três mestrados profissionais e 18 turmas de pós-graduação lato sensu à distância ofertadas, em seis pólos. 
Ao longo desse percurso, a UNEMAT tem desenvolvido ações pioneiras com intuito de atender às demandas emergentes e específicas do Estado. Uma primeira ação foi desenvolvida no Campus de Barra do Bugres, por meio da Diretoria de Educação Indígena, ofertando desde 2001 cursos de licenciaturas específicos e diferenciados para mais de 30 etnias.

A segunda ação pioneira foi a criação do Programa Parceladas em 1992 projeto foco de nossa pesquisa. $\mathrm{O}$ projeto tem apresentado uma modalidade diferenciada de ensino com a finalidade de atender à demanda emergente de formação de professores em diferentes regiões do Estado. O modelo de formação presencial é oferecido em regime parcelado, modular ou em regime contínuo; modelo este que serviu de base para outras universidades brasileiras.

A terceira ação refere-se ao ensino à distância que passou a ser ofertado pela UNEMAT a partir de 2001, com fim de atuar na formação de professores da rede pública por meio dos cursos de Pedagogia e de Educação Infantil. A partir de 2010, a instituição integrou o Sistema Universidade Aberta do Brasil (UAB), passando a ofertar cursos de formação inicial e pósgraduações que beneficiam toda a comunidade.

Recentemente, tem-se cogitado a implantação de campi nas cidades de Várzea Grande, Rondonópolis e Cuiabá. Entre todos os estados brasileiros que possuem uma Universidade estadual, o Estado de Mato Grosso é o único que não possui campus em sua capital.

Ao longo dos anos, o vestibular foi a única forma de ingresso nos cursos da universidade. Todavia, em junho de 2012, a Universidade fez a adoção ao Sistema Seleção unificada (SISU) que utiliza a nota do Exame nacional do Ensino Médio (ENEM) como forma de ingresso.

Todo esse percurso histórico, pelo qual passou a Universidade, foi importante para o surgimento e consolidação do Programa Parceladas, conforme relata Costa, (2000. p.14). “Todos os acontecimentos citados vêm somar ao Projeto de Licenciatura Plena Parceladas na ampliação e consolidação de uma universidade voltada à formação de professores nas várias regiões do Estado, dando prioridade aos lugares onde a formação superior é de difícil acesso à população".

A UNEMAT apresenta uma filosofia da interiorização, ou seja, "do interior para o interior", pois tem a sede na cidade de Cáceres, interior do Estado. Ela está presente em diversas regiões geo-educacionais de múltiplas diversidades geográfica, econômica, social, cultural e apresenta-se como espinha dorsal das áreas da educação e do meio ambiente. Assim, a contribuição da universidade para a população mato-grossense é bastante relevante, principalmente para o interior de Estado, pois contribui na formação de dezenas de profissionais. 


\section{O Cenário histórico da situação educacional que antecede o período do surgimento do}

\section{Projeto Parceladas: (Década de 1980-1990)}

Para entender o surgimento do Programa Parceladas é preciso rever um pouco do processo histórico da educação na região do Araguaia e as legislações vigentes que referem à formação de professores tanto no âmbito nacional quanto estadual e regional.

O processo de colonização das várias regiões do Estado de Mato Grosso, no período de 1972 a 1983, deu-se por migrantes sulistas e nordestinos que foram atraídos pelos projetos de colonização surgidos no Estado, principalmente, pelo Instituto Nacional de colonização e Reforma Agrária (INCRA) que na época tomou o controle da colonização da região amazônica, por meio de pequenos assentamentos rurais. A colonização da região iniciou-se após a construção da BR 163, conhecida como Cuiabá - Santarém.

O processo acelerado da colonização do Estado de Mato Grosso foi bastante intenso. Em 1979 houve a divisão do Estado de Mato Grosso em dois estados, criando o Estado do Mato Grosso do Sul. Nessa época, o estado de Mato Grosso contava com 38 municípios, passando para 96 no ano de 1988; em menos de uma década quase triplicou o número de municípios. (COSTA, 2000).

Com o intenso processo de colonização e com a criação de cidades e vilas, consequentemente aumentou o número populacional que trouxe problemas à educação como escolas precárias e insuficientes para atender à demanda educacional, da época; e para agravar ainda mais o problema educacional, não havia um quadro de profissionais qualificados.

Na década de 1970 e 1980, os professores que se dispuseram a atender a educação eram pessoas, sem formação, vindas do interior dos estados brasileiros, possuindo apenas o primeiro grau, mas contavam com boa vontade para atender nas diversas localidades da região. As comunidades indicavam seus professores pela capacidade mínima de leitura, habilidade de realizar as operações simples de matemática e pela participação nas ações da comunidade. Devido à falta de professores ou até mesmo pela quantidade de aluno em cada localidade, a maioria das salas de aula, da zona rural, era multisseriada ${ }^{2}$. O nível de evasão e reprovação eram elementos recorrentes.

\footnotetext{
${ }^{2}$ Multisseriada, denominação dada quando um único professor ministrar aulas para vários níveis de ensino em uma única sala de aula.
} 
Segundo Costa (2000), o Estado deixou de atender a educação do Araguaia. Enquanto a população crescia, não eram criadas escolas e nem professores eram formados para exercer a docência. Com isso, surgiram vários movimentos como: sindicatos, associações, cooperativas, movimentos sociais e até mesmo a igreja católica envolveu-se, reivindicando melhoria educacional, como por exemplo, a construção de escolas e, principalmente, qualificação dos professores leigos.

A região do Araguaia, desde a década de 1960, tem lutado por uma Educação de qualidade com planejamento e formação de cronograma no desenvolvimento de ações que busquem a melhoria da educação na região, como se pode verificar na descrição do cronograma a seguir:

1. As origens da luta (1965 -1970). Primeira experiência de educação. A criação do Ginásio Estadual do Araguaia.

2. Educação e lutas sociais na região (1971). O início da educação de adultos no sertão de São Felix do Araguaia.

3. A luta por uma educação e o ensino público (1976). Expansão e fortalecimento das escolas municipais.

4. A formação de professores ( $1^{\circ}$ grau): curso de férias (1978).

5. Proposta educativa no âmbito das prefeituras populares (1982). Relações com a Secretaria Estadual e universidade.

6. Novas estratégias. A perda das "prefeituras populares". Relação com a Secretaria Estadual de Educação. Projeto Inajá ("Memorias", 1, 1990) citado por (COSTA 2000. p. 37).

Em busca de qualificar os professores leigos, foram criados projetos em nível de magistério como o Projeto Logos II - Curso Supletivo em 1980, em articulação com as secretarias municipais de educação. Contudo, o curso não conseguiu cumprir a função de proporcionar habilitação legal à maioria dos professores, nem melhorar a qualificação da educação na região (GENTIL, 2002).

Nesse cenário não muito animador, em 1985 aconteceu um encontro, em São Félix do Araguaia, para discutir a situação da Educação no Araguaia. O encontro teve ênfase nas novas perspectivas para o ensino de Ciências e Matemática, buscando um curso que atendesse as comunidades, urbana, rural e indígena. Uma equipe de professores da Universidade Estadual de Campinas (UNICAMP) norteou os trabalhos juntamente com coordenadores pedagógicos dos municípios que foram capacitados para retornar aos seus municípios e trabalhar com os professores.

A equipe Pedagógica solicitou o assessoramento da equipe de professores da UNICAMP e a possibilidade da participação dos professores de vários municípios na qualificação continuada que acontecia em período de férias. 
A semente por uma educação de qualidade e, especificamente, por uma formação dos profissionais atuantes na educação foi plantada por meio de uma luta constante e da criação de projetos. Com isso "o Projeto Inajá ${ }^{3}$ nasceu da necessidade de fazer uma escola diferente que valorizasse também o docente" (CAMARGO, 1997, p. 22). O Projeto Inajá foi desenvolvido no período de 1987 a 1990 com objetivo de formar os professores em serviço, nas séries iniciais, que atuavam nas escolas rurais, indígenas, possibilitando uma formação em nível médio.

Esse projeto apontava para uma educação que levasse em consideração as características regionais, ajustado assim, na precisão de fazer uma escola diferente que considerasse os conhecimentos vivenciados pelos professores da região do Médio Araguaia.

Com muita dificuldade, o Projeto Inajá representou o princípio da qualificação profissional dos professores da região, associando e utilizando as experiências de vida e de conhecimento vivenciados por cada professor-aluno em etapas de formação inicial ou continuada.

O projeto Inajá formou professores habilitados em magistério que agrupavam experiências da formação inicial e da prática docente. Após terem adquirido a formação em nível de magistério, os professores, em sua maioria, atuavam em outros espaços educativos ou de luta como nos sindicatos e na igreja. Não se contentando com a qualificação secundária, esses professores almejavam algo a mais e começaram os embates na luta pela continuação da formação profissional. Em meio a esse contexto de luta, os professores foram atendidos em nível de Terceiro Grau.

Arguello (1999) assegura que o Inajá foi um ensaio educacional bem sucedido e que apresentou bons resultados devido ao apoio de grandes parceiros, como a UNICAMP, Secretarias municipais e Secretaria Estadual de Educação; e que a partir de então, nasceu uma postura inovadora, fortalecida e continuada por meio do Projeto Parceladas.

O primeiro Projeto de Licenciaturas Plena Parceladas foi elaborado em 1990 como resultado da participação da UNEMAT e da Secretaria de Educação em dois seminários que buscavam elementos para a solução das reclamações feitas pelos participantes do Inajá.

${ }^{3} \mathrm{O}$ nome INAJÁ origina-se do nome de uma palmeira que renasce mesmo após ser queimada. Ela brota “numa situação adversa, sem água no tempo de seca” (CAMARGO, 1997, p. 17). Nome que remete a um modelo de duelo e de resistência que brota nos professores sem qualificação, a esperança em se tornarem profissionais capacitados para exercer a docência. 
Nessa mesma época, entre as décadas de 1980 e 1990, o país adotou o compromisso em nível mundial com a proposta de "Educação Para Todos", fase em que foi criado o Plano Nacional de Educação - PNE regulamentado pela Lei n 10.172 e aprovado em 9 de janeiro de 2001, pelo Presidente da República. A sociedade civil foi chamada para participar da elaboração desse plano decenal de educação. Os movimentos sociais e as organizações em nível nacional como a UNDIME, CNTE, ANFOPE, ANDES, Conselho Nacional de Secretários Municipais, entre outros tiveram grande participação nesse período e foram determinantes e responsáveis por diversas conquistas.

Reis (2007) diz que além das indicações e dos financiamentos do Banco Mundial para a formação de professores leigos foi promulgado mudanças nessa formação, através da Lei de Diretrizes e Bases da Educação Nacional (LDB 9.394/96). A autora cita Souza e Silva (2001) e Brandão (2003), fazendo referência a mudanças na proposta da LDB que determina uma exigência continua de uma capacitação em nível superior para todos osprofessores.

No parágrafo $4^{\circ}$ do art. 87 das Disposições Transitórias descreve que: “Até ao fim da Década da Educação (1997 - 2007) somente serão admitidos professores habilitados em nível superior ou formados por treinamento em serviço". Com a exigência da legislação vigente, Municípios, Estado e União deveriam concretizar projetos de formação de professores com intuito de qualificá-los em exercício.

Assim como no País, o Estado de Mato Grosso aderiu às discussões e lutas pela qualificação profissional e pela melhoria da qualidade de ensino. Os profissionais da Educação mobilizaram-se em todo o Estado com objetivo de reunir e debater a profissão, o plano de carreira e a qualificação. Nesse sentido, surge o Sindicato dos trabalhadores do ensino público de Mato Grosso (SINTEP), promovendo vários encontros e debates, apoiando greves e mobilizações. Com essa movimentação e participação nas discussões nacionais, conseguiu na década de 1990 a aprovação da Lei Orgânica para os Profissionais do Ensino Básico (LOPEB) no Estado, ganhando projeção e respeito da categoria.

No intuito de atender às exigências da legislação vigente, tanto da LDB quanto do PNE em relação à formação de professores, a UNEMAT começou a mobilizar-se a partir do seminário de expansão que aconteceu em 1990, conforme já relatado neste texto. Desse modo, surge o Projeto de Licenciaturas Plenas Parceladas no recém-criado campus do Médio Araguaia, em Luciara, distante aproximadamente um mil e quinhentos quilômetros da sede da universidade. Assim, desde 1992 tem atendido a demanda e os requerimentos da população do interior do Estado no que refere à formação de professores leigos e aos egressos do Ensino Médio. 


\subsection{O Programa Parceladas e seu Percurso Histórico}

Pensando na formação de professores de forma diferenciada da maioria das Universidades e que contempla uma proposta voltada para a valorização do conhecimento empírico dos professores, na região do Médio Araguaia foi institucionalizado o Projeto Parceladas, Projeto de Formação em Rede, em Serviço e Continuada: Licenciaturas Plenas Parceladas.

O Projeto Licenciatura Parceladas originou-se em meio às reivindicações da população que almejavam a qualificação docente e a melhoria das condições de trabalho. Assim, as mudanças iniciaram-se com a construção do processo histórico da Educação no Estado e dos duelos em defesa da escola pública e da formação de professores ${ }^{4}$. A partir da solicitação do grupo de professores, recém-formados pelo Projeto Inajá, que queriam dar continuidade aos estudos em nível de terceiro grau, requereu-se junto a Universidade Estadual do Mato Grosso (UNEMAT) a criação de um curso de formação de professores em nível de graduação na região.

No ano de 1990 com a realização do I Seminário de Expansão do Ensino Superior Estadual para discutir a expansão do ensino superior no Mato Grosso e com a implantação do Projeto Parceladas, a UNEMAT criou, na cidade de Luciara, o Núcleo de Apoio Educacional do Médio Araguaia, local destinado as atividades letivas ${ }^{5}$. Nasce, então, em 1992, na região do Médio Araguaia, o Projeto de Formação em Rede, em Serviço e Continuada: Licenciaturas Plena Parceladas apoiado por um grupo de pesquisadores/professores da UNICAMP e da Universidade de São Paulo (USP) que ajudou a colocar em prática a idéia juntamente com uma instituição de ensino superior, que ainda não tinha conquistado o título de Universidade, a UNEMAT e com a parceria da Secretaria de Educação do Estado - SEDUC, dos gestores públicos dos municípios que compunham uma mesma região geo-educacional, a saber, composta por 13 (treze) municípios: Alto da Boa Vista, Bom Jesus do Araguaia, Confresa, Canabrava do Norte, Porto Alegre do Norte, Luciara, Novo Santo Antônio, Santa Cruz do

\footnotetext{
${ }^{4}$ Os anos de 1970 a 1980 aconteceram embates difíceis para a Educação no Estado. Esse período trata-se de uma fase que precede a implantação do Projeto Parcelada e sua importância na formação dos professores do Médio Araguaia.
}

\footnotetext{
${ }^{5}$ A sede administrativa geral do Projeto foi instalada no campus de Cáceres a uma distância de quase 1.600 Km do núcleo pedagógico de Luciara (SOUZA, 2009).
} 
Xingu, Santa Terezinha, São Felix do Araguaia, São Felix do Xingu, Serra Nova Dourada e Vila Rica.

O Projeto original do Programa Parceladas programou cursos de licenciatura plena na modalidade diferenciada, contemplando as características da região e do Estado, com efetivação da proposta teórica/metodológica solicitada. Foram oferecidos, inicialmente, apenas três cursos de licenciatura: Matemática, Letras e Pedagogia que eram considerados emergentes para atender a demanda da região, tanto na rede pública de ensino estadual quanto municipal; outros fatores evidenciados no planejamento do curso foram a permanência do licenciado em sala de aula, a garantia da continuidade do seu trabalho, o investimento de recursos financeiros de cada município, a distância entre os municípios, a falta de professores formadores na região.

A organização dos cursos deveria garantir a permanência do Licenciado por meio da oferta do mínimo de condições necessárias para a realização dos trabalhos, com a instalação de um núcleo em uma das cidades, local em que os licenciados iriam estudar durante as férias escolares (SOUZA, 2009).

Após a finalização dos três primeiros cursos de licenciaturas, foram oferecidos mais três cursos: História, Biologia e Geografia com o intuito de continuar o atendimento à demanda da região.

No ano de 2003 (ano dessa pesquisa), foram oferecidos seis cursos de licenciaturas (Matemática, Letras, História, Geografia, Biologia e Pedagogia) simultaneamente, pois os cursos oferecidos anteriormente foram insuficientes para atender aos professores leigos. Nessa etapa de oferta de cursos, o Campus do Médio Araguaia da UNEMAT abriu dois Núcleos Pedagógicos, um na cidade de Confresa e outro na cidade de Vila Rica. Houve também a distribuição dos seis cursos nos três locais, sendo Licenciaturas em Biologia e Geografia no campus da UNEMAT, na cidade de Luciara, Letras e História no Núcleo pedagógico de Confresa e Matemática e Pedagogia no Núcleo Pedagógico de Vila Rica.

Após a finalização desses cursos, ainda na busca de alternativas, o Programa Parceladas abriu, em 2007, duas turmas na região do Médio Araguaia, ofertando 50\% das vagas para formar professores leigos, ou seja, professores sem formação, mas que já atuavam na docência e 50\% para os egressos do Ensino Médio, nas áreas de licenciaturas em Letras, ofertado no núcleo de Confresa, licenciatura em Matemática ofertado no núcleo de Vila Rica e licenciatura em Química ofertada no campus do Médio Araguaia em Luciara.

No ano de 2011 foram ofertados mais cinco cursos de Licenciaturas para a região, sendo uma turma de Química para o Campus de Luciara; em Confresa foi ofertada mais um curso de Letras e houve também a oferta de cursos inéditos para a região como Licenciatura em Ciências 
Sociais, em Confresa e Licenciatura em Educação Física e Ciência da Computação, no Núcleo de Vila Rica.

Após ser efetivado na região do Araguaia, o Projeto avançou para outras regiões pólos como Colíder, Barra do Bugres, Alta Floresta, Rosário Oeste, Araputanga, Comodoro, Poconé, Vila Rica, Confresa e Matupá.

A partir de 2012, o Projeto Parceladas, atendeu também a proposta de adesão da Universidade para o Plano de Ações Articuladas $\left(\mathrm{PAR}^{6}\right)$ do Estado de Mato Grosso em atendimento ao Decreto $N^{\circ}$ 6.094, de 24/04/07 que dispõe sobre a implementação do Plano de Metas Compromisso Todos pela Educação do Plano de Desenvolvimento da Educação (PDE) do Ministério da Educação. No sentido de continuar atendendo a uma demanda, o Projeto, passou a oferecer cursos de $1^{\mathrm{a}}$ Licenciatura e $2^{\mathrm{a}}$ licenciatura na modalidade presencial, atendendo aos critérios e às demandas nos locais estabelecidos pelo PAR/FOR - Programa Emergencial de Formação de Professores da Educação Básica em exercício.

A proposta curricular para as ações pedagógicas do Programa Parceladas foi construída aos poucos e teve como suporte teórico as ideias de Demo (1996) que diz que a concepção de pesquisa no ensino deve ter atenção ao processo social que transcorre por toda a vida acadêmica e se incorpora nas ações do professor e do aluno, qual seja a pesquisa; a qual necessita ser constituída pelo professor em formação, em sua formação inicial e ter sua permanência no fazer pedagógico; o que poderá permitir ao professor maior compreensão da complexidade do fazer pedagógico do seu trabalho na escola. Assim, a pesquisa passou a ser a espinha dorsal para todos os cursos (SOUZA 2009).

O projeto Parceladas da região do Araguaia pode ser considerado um projeto diferente de todos os outros Projetos dessa modalidade que aconteceram no país, pois sua proposta curricular que, caracteriza as grandes linhas da ação pedagógica no Programa, foi idealizada em uma perspectiva sócio-histórico da produção do conhecimento (PROCESSO DE RECONHECIMENTO DO CURSO 2011).

Nesse sentido, o Projeto Parceladas após 27 anos de seu surgimento, habilitando profissionais na educação em quase todo o Estado e principalmente na região do Araguaia, consolidou-se e fortaleceu-se, fato esse que não aconteceu com os demais Projetos Parceladas

\footnotetext{
${ }^{6}$ O PAR caracteriza-se em instrumento que se estabelece e se concretiza por meio do regime de cooperação entre governos municipais, estaduais e federais e das instituições públicas formadoras de professores, no sentido de desenvolver açõesque operar na mobilização social pela melhoria da qualidade da educação básica.
} 
instituídos em todo o país. O Projeto consolidou-se e deixou de ser Projeto para se tornar um Programa. Conforme refere Arruda (2010)

\begin{abstract}
A atuação das Parceladas ganha visibilidade, não apenas pela extensão nas várias regiões do estado onde se insere, mas, sobretudo, pela qualidade da formação que oferece. Com isso, deixou de ser ao longo dos anos um mero projeto para se tornar um programa, que a UNEMAT institucionalizou como política de formação de professores, consolidando-se a cada turma que se abria (ARRUDA, 2010, p. 37-38).
\end{abstract}

Acredita-se que por ter deixado de ser um simples Projeto para tornar-se um Programa, instalou-se, então, o diferencial do Programa Parceladas da Universidade do Estado de Mato Grosso que atua na formação de professores, visão essa que segundo Costa (2000) o projeto se diferencia dos outros projetos parceladas ou modulares por sua característica e seus objetivos, procurando atender às regiões de acordo com a necessidade e suas características próprias.

Para a solidificação e fortalecimento do projeto fez-se necessário realizar mudanças no modelo de formação com intuito de atender as demandas que foram surgindo e também para adequar-se ao novo público. Todavia, há a necessidade de cursos de Graduação para formação de professores que propicie a constituição de modelos didáticos, estilos, competências e atitudes de organização adequadas ao que se pretende que o futuro professor exerça em suas práticas pedagógicas.

Historicamente, os cursos do Programa Parceladas ofereciam formação para Professores que possuíam vínculos no Sistema de ensino Municipal e/ou Estadual dos municípios consorciados da região, em torno do Campus Universitário que tem a função de coordenar as ações do projeto. Hoje, com intuito de atender as demandas do ensino superior, em relação aos alunos egressos do Ensino Médio, o Programa de Licenciaturas Plenas Parceladas expande sua ação na oferta de vagas à comunidade em geral. E, ainda, além de ampliar os cursos de licenciatura, também, tem ofertado cursos de bacharelado em algumas regiões, conforme a demanda e os convênios com os municípios.

Toda luta educacional voltada para a formação inicial de professores, na Região do Araguaia, relaciona-se à história de luta pela terra e pela educação protagonizada pelos movimentos sociais, pela Prelazia de São Felix do Araguaia e, sobretudo, pela figura tão importante, nesse contexto histórico, do bispo emérito Dom Pedro Casaldáliga que incansavelmente atuou na defesa de uma educação pública e de qualidade. Em um relato de Dom Pedro, em uma entrevista concedida a uma jornalista da Unemat, no ano de 2011, o bispo justificou seu papel na luta em defesa da educação pública, alegando ser esse o principal clamor dos povos do Araguaia em que o propósito era "Que não esquecesse a educação". Acreditava 
que lutar pela posse da terra não era suficiente para consolidar a reforma agrária e a prosperidade da vida no campo.

Dom Pedro, também atuou veemente na expansão da Universidade do Estado de Mato Grosso em defesa da criação e consolidação do campus Universitário do Médio Araguaia, ajudando a tirar do esquecimento "o Vale dos esquecidos" ". Tanto em suas ações quanto em suas falas reconheceu a relevância do Programa Parceladas para a formação inicial de professores, pois atua "com o pé no chão da sala de aula".

O magistério é uma referência onde se cruzam muitas histórias de vida tão diversas e tão próximas. Um espaço de múltiplas expressões.[...] Somos um coletivo[...].Somos o lugar onde nós fizemos, as pessoas com quem convivemos. Somos a história de que participamos. A memória coletiva que carregamos (Arroyo, s/p. 2001).

Muitos egressos do Programa reconhecem a importância de Dom Pedro Casaldáliga tanto na luta pela terra quanto pela implantação e consolidação de uma formação pautada nas características regionais. Nesse sentido, têm-se inúmeros trabalhos monográficos mencionando esse reconhecimento e a própria Universidade tem reconhecido essa luta em defesa do Campus Universitário do Médio Araguaia e pelos direitos dos indígenas e da população mais pobre que concedeu seu primeiro título honorífico: O título de Doutor de Honoris Causa ao Bispo Emérito da Prelazia de São Felix do Araguaia.

\subsection{O reconhecimento dos Egressos dos cursos de licenciatura em Matemática ao Programa Parceladas}

Na época da implantação do Projeto Parceladas, a região do Médio Araguaia no Mato Grosso era apontada pela falta ou restrições de alguns serviços básicos, como saúde, segurança, justiça, trabalho e, principalmente, educação. Percebe-se que a geografia se estabelecia como outro problema, pois dificultava o acesso a esses serviços. Assim, as atividades educacionais quando chegavam à região, causavam e ainda causam impactos positivos como se pode destacar a história do Projeto Inajá (GENTIL, 2000).

Os sujeitos de nossa pesquisa estão inseridos nessa configuração de espaço. São espaços que constituem e vão desenhando suas histórias de vida, seja social, pessoal e ou profissional.

\footnotetext{
${ }^{7}$ Terno utilizado pela população no Vale do Araguaia e entre políticos do Estado de Mato Grosso. Significa uma região não atendida pelas políticas públicas, sendo esquecida pelos políticos e ainda pelos conflitos entre brancos e indígenas na disputa pela terra. A avaliação é de antigos e novos líderes políticos e prefeitos "dos Esquecidos", segundo os quais a "falta de respeito e de sensibilidade política" dos sucessivos governos (tanto em âmbito estadual quanto no federal) é "gritante.
} 
Pois, é desse modo que acontece a interação com seus pares, colegas de estudo, de profissão e com os demais moradores da região.

O Programa Parceladas ao longo dos tempos tem procurado desenvolver a formação de professores com propostas educacionais que valorizem o sujeito, tendo por base uma perspectiva que adota diversas competências como o poder de participar, sugerir, determinar e criar. Com intuito de conhecer a visão dos egressos sobre o significado do Programa para a região, apresentamos relatos dos egressos que mostram a importância e o reflexo da formação do Programa para a região em que vivem. Para organizar esses diferentes olhares, optamos por analisá-las separadamente, por turmas, considerando o perfil diferenciado de cada uma.

Para a turma 2007 ficou bem evidente que o programa contribuiu para a melhoria da educação na região do Araguaia, "O início de um grande desenvolvimento na educação da região do Araguaia. Um divisor de água na educação desses municípios" (EGRESSO 5).

Assim, 74\% dos egressos consideram que o Programa contribuiu para a melhoria na qualidade de ensino de forma em geral, como podemos verificar na fala a seguir: "A melhora na qualidade de ensino, valorização da docência, acho que em todos os municípios, e principalmente o reconhecimento pela sociedade como profissionais habilitados para ensinar", (EGRESSO 15).

O Programa Parceladas foi considerado um divisor de águas para atender a demanda emergente na formação inicial de professores. Nota-se, também, que o projeto contribuiu para "um grande avanço no Ensino da Matemática, acredito que supriu grande parte da demanda que existia nas escolas da Região do Baixo Araguaia, em busca de professor qualificado para trabalhar está disciplina nas escolas públicas, desta parte do Estado de Mato Grosso, (EGRESSO 12). Considera que a oportunidade de formação proporcionou "a realização de muitos sonhos acalentados e a possibilidade de uma melhoria significativa no ensino matemático de qualidade” (EGRESSO 13).

Na visão dessa turma, além de melhorar a qualidade de ensino, também interferiu nos fatores sociais, culturais e econômico da população como podemos verificar na fala do egresso 6: "Desenvolvimento da Educação, da cultura e economia de modo direto e indireto", e principalmente dos profissionais da educação que sempre teve uma baixa estima. "A melhora na qualidade de ensino, valorização da docência, acho que em todos os municípios, e principalmente o reconhecimento pela sociedade como profissionais habilitados para ensinar" (EGRESSO 11).

Para a turma 2007, em que todos já exerciam a profissão, o Programa Parceladas significou a oportunidade de realizar uma graduação, de continuar a formação para assegurar a 
profissão, bem como proporcionou uma abertura de novos horizontes e principalmente mudanças no processo ensino aprendizagem. Considera também que "Por ser uma formação em exercício possibilitou aos educadores o confronto entre a teoria e a pratica" (EGRESSO 7), e ainda "possibilitou grandes pesquisas, trocas de experiências, formação e continuação de estudos para muitos professores desse Araguaia” (EGRESSO 10), ocasionou assim, "uma possibilidade impar aproximando a formação e qualificação profissional" (EGRESSO 10), provocando assim um grande avanço no sistema educacional da região do Araguaia. "Foi muito importante, (...) visava formar profissionais da área que não tiveram oportunidade de se qualificar profissionalmente para poderem atuar como educadores na rede municipal $e$ estadual, assim como deu oportunidades a outros que ao saírem do ensino médio não tinham oportunidades de se qualificarem por não terem condições de saírem do município para buscar qualificação desejada” (EGRESSO 21).

A formação inicial de professores proporcionada pelo Programa Parceladas, segundo a turma 2011, significou, principalmente, a oportunidade de ter uma formação em nível de graduação sem ter que sair da cidade em busca de formação e também a abertura de vagas para os egressos do ensino médio como uma oportunidade para as pessoas que não atuavam na educação; habilitando-os para atuar na educação do município como podermos verificar na fala a seguir: "Oportunidade a formação superior aos concluintes do ensino médio, pontos positivo na imagem da cidade com os projetos estaduais, e mais importante a consolidação de profissionais habilitados para a formação da cidadania de cada educando” (EGRESSO 9)

Verifica-se também que o Programa "Ajudou a estabelecer uma melhor relação com o meio social, e a sociedade se sentiu parte da escola" (EGRESSO 17). Nesse Sentido, o Programa Parceladas tem cumprido com seu propósito e ainda foi um avanço significativo na educação do município, habilitando profissionais para atuarem no ensino de Matemática, suprindo assim a deficiência de profissionais capacitados, e com isso, proporcionando uma melhoria na qualidade de ensino: "O projeto contribuiu para a região formando profissionais capacitados na área de matemática e consequentemente para um ensino de melhor qualidade nesta área do conhecimento, já que antes do projeto esta região tinha poucos profissionais habilitados em matemática” (EGRESSO 11).

Também significou oportunidade de adquirir conhecimento, facilitando a oportunidade de conseguir um emprego, melhorando a qualidade de vida dos egressos. Pode-se notar na fala de um egresso: "Foi bastante importante, pois temos hoje mais oportunidade de emprego onde quem concluiu estão todos bem empregados e estabelecidos financeiramente" (EGRESSO 6). E ainda completa outro egresso: Significou muito, porque deu oportunidade de formação para 
muita gente e essa graduação somada ao um maior conhecimento resultou uma melhor condição de trabalho e de vida para todos (EGRESSO 15).

Percebe-se que o Programa foi de grande relevância para a turma 2011 "pois hoje temos mais profissionais trabalhando na área da educação matemática, até mesmo para os que não estão atuando na educação acredito que foi importante, pois todos os colegas que formaram hoje estão todos trabalhando e estão bem estabilizados "(EGRESSO 3). Assim como foi para a turma anterior, para esta o projeto foi bastante significativo, pois proporcionou a qualificação em nível superior, possibilitando o ingresso na educação para os que desejavam e dando oportunidade em outras áreas para os que não pretendiam ser professor.

Nessa perspectiva, além de cumprir com o seu papel educacional o Programa tem cumprindo com o papel social, levando oportunidade de emprego, melhoria na qualidade de vida aos egressos e refletindo nas questões sociais dos moradores da região.

O magistério é uma referência onde se cruzam muitas histórias de vida tão diversas e tão próximas. Um espaço de múltiplas expressões.[...] Somos um coletivo[...].Somos o lugar onde nós fizemos, as pessoas com quem convivemos. Somos a história de que participamos. A memória coletiva que carregamos (ARROYO, 2000, 14).

Assim, a concepção de formação inicial de professores no Programa Parceladas, segundo Souza (2009), teve e ainda tem como finalidade permitir que o licenciando seja um sujeito ativo no processo da construção e desenvolvimento profissional como professor, constituindo-se de competências através das ações realizadas durante e após a formação inicial, especificamente, tendo a pesquisa como instrumento pedagógico que lhe possibilite ensinar com mais qualidade; permite também, mais capacidade de tornar-se um aprendiz com as práticas em sala de aula e transitar por outras áreas do conhecimento, tendo uma visão expandida da realidade, além da autonomia para buscar o aprofundamento e o embasamento teórico dos conteúdos matemáticos.

\section{Considerações}

Os depoimentos, os dados e as análises contidas neste artigo possibilitaram o entendimento do processo de origem, de transformação e de expansão da UNEMAT, especificamente do Programa Parceladas, bem como das lutas e das alianças que contribuíram para o fortalecimento do Programa, em estudo, e consequentemente da Universidade. 
O grande desafio da Educação perpassa pela formação do professor e pela educação de qualidade que deve ser amparada, sustentada, alimentada, defendida por professores preparados e comprometidos com a aprendizagem dos alunos. No intuito de atender a esse desafio foi que os povos do Araguaia, em luta incansável e incessante por uma educação de qualidade, reivindicaram formação para os professores leigos na docência.

Em atendimento as reivindicações dos movimentos sociais, dos povos do Araguaia, a Unemat implantou e consolidou o Campus do Médio Araguaia, por meio do Programa Parcelada em 1992. A partir de então, tem contribuindo com a região do Araguaia, formando professores qualificados para atuarem e defenderem uma educação igualitária e de qualidade.

Com o passar do tempo, a atuação do Projeto Parceladas ganhou visibilidade não apenas pela extensão nas várias regiões do Estado em que se insere, mas, sobretudo, pela qualidade da formação que oferece. Isso se torna visível na ação dos egressos que se destacaram nas instâncias de atuação e nos processos seletivos que concorrem.

Com isso, deixou de ser ao longo dos anos um mero projeto para se tornar um programa em que a UNEMAT institucionalizou como política de formação de professores. Os cursos de licenciaturas oferecidos pelo programa foram pensados com um calendário próprio, distribuídos em momentos intensivos e momentos intermediários, planejados de acordo com os calendários dos municípios consorciados.

Dessa maneira, a UNEMAT foi fortalecendo-se no interior. Sua expansão auxiliou na transformação da realidade social dos professores, pois toda trajetória de movimentação dos grupos sociais no Araguaia foi acompanhada da relação com a educação, em especial, com a formação de professores.

O Programa Parceladas é um projeto histórico condicionado às circunstâncias, ao tempo/espaço cotidianos onde a Escola está inserida, às crenças, enfim, a tudo o que faz pulsar os indivíduos de uma sociedade. Após 27 anos de implantação do Programa Parceladas configura-se como uma das estratégias-chaves da renovação educacional pretendida em Mato Grosso.

Destaca-se a relevância do Programa Parceladas enquanto política pública educacional que busca a melhoria da qualidade da oferta pública do Ensino Superior no Estado de Mato Grosso ao propor mudanças significativas na educação, prevalecendo práticas pedagógicas que respondam a uma demanda atual, atendendo as necessidades locais e regionais voltadas aos interesses da comunidade, priorizando a formação inicial, indicando sujeitos de referência em produções sociais, culturais e políticas nas áreas de formação ofertadas pela Universidade na região. 


\section{Referências}

ARGUELLO, Carlos Alfredo. Artigo de apresentação das Parceladas. Disponível em: <http://www.unemat.br> Acessado em 20 out. 2013.

ARROYO, Miguel G. Ofício de mestre: imagens e auto-imagens. $3^{\text {a }}$ edição. Petrópolis: Vozes, 2001. 2000.

Miguel. Ofício de Mestre - Imagens e Auto-Imagens. Petrópolis, RJ: Vozes,

ARRUDA. Adson. Et.al. O ensino pela Licenciatura Parceladas e os novos desafios. In. SILVA, Agnaldo Rodrigues; KARIM, TaisirMahmudo. (Org.). Universidade e política temas do ensino. 1. ed. Cáceres: Ed. UNEMAT, v. 1. 2010, p. 35-56.

BOGDAN, R.; BIKLEN, S. K. Investigaçãoqualitativa em educação: uma introdução à teoria e aos métodos. Trad. Maria J. Álvares, Sara B. dos Santos eTelmo M. Baptista. Porto: Porto Editora, 1994.

BRASIL. Lei no 9.394, de 20 de dezembro de 1996. Estabelece as Diretrizes da Educação Nacional. Diário Oficial da União, Brasília, 23 dez. 1996.

CAMARGO, D. M. P. Mundos entrecruzados: Projeto Inajá - uma experiênciacom professores leigos no Médio Araguaia. Campinas: Editora Alínea, 1997. 230p.

COSTA, José Ferreira da. A Experiência Educacional na Universidade do Estado de Mato Grosso: Projeto de Licenciatura Plena Parceladas. Marilia: 2000. 263p. Dissertação de Mestrado (Mestrado em Educação) Faculdade de Filosofia e Ciências, Campus de MARILIA, Universidade Estadual Paulista "Júlio de Mesquita Filho".

GENTIL, Heloisa Salles. Re-significando identidades de professores no encontro com o Projeto Parceladas. Projeto de Dissertação de Mestrado. Porto Alegre: PPGEdu/Faced/UFRGS, 2000.

GENTIL, H. S. Formação docente - no balanço da rede entre políticas públicas e movimentos sociais. 2002. 130 f. Dissertação (Mestrado em Educação). Faculdade de Educação, Universidade Federal do Rio Grande do Sul, Porto Alegre, 2002.

LUDKE, M; ANDRE, Marli E. D. A. Pesquisa em educação: abordagensqualitativas. - São Paulo, SP: EPU, 1986, 99 p.

MATO GROSSO. Processo de Reconhecimento do curso de Licenciatura em Matemática, Programa Parceladas. Vila Rica, MT: UNEMAT, 2011.

Instrução Normativa 004 de 05 de outubro de 2011. Disponível $\mathrm{em}:\langle$ http://www.unemat.br/proeg/docs/instrucao_normativa_004_2011.pdf $>$. Acesso em 20 out. de 2014.

REIS. Maria Elídia Teixeira. Formação de Professores Leigos em Serviço: Um estudo sobre saberes e práticas docentes em Geometria. Dissertação de Mestrado. UNICAMP. Campina/SP. 2007. 
SOUZA, Josimar de. A construção da identidade profissional do professor de Matemática no Projeto de Licenciaturas Parceladas da UNEMAT/MT. São Paulo. 2009. 287p. Tese (Doutorado em Educação Matemática).Pontifícia Universidade Católica de São Paulo, PUC/SP.

UNEMAT- Universidade do Estado de Mato Grosso. Histórico. Cáceres-MT. Disponível em: <www.novoportal.unemat.br>. Acesso em: 05 out.13 